\title{
Non-past referring Imperfects in the \\ New Testament: A test case for an anti- anti-anti-Porter position
}

\author{
G J Swart \\ Department of Ancient Languages \\ University of Pretoria
}

\begin{abstract}
Since the publication more than a decade ago of two comprehensive studies on verbal aspect in New Testament Greek (Porter 1989; Fanning 1990), scholarly discussion has tended to focus more on the differences than on the agreements between these theorists. Ironically, the main point of dispute has become not their different views of the notion of 'aspect', but the question whether or not the tense forms of the indicative mood systematically convey temporal meaning. In this study an attempt is made to clear up some of the resulting confusion. The scope of the study is limited to New Testament passages containing imperfect tense forms which, according to Porter, do not refer to past time. Porter's interpretation of these passages is discussed and compared with the opposing views of a number of scholars.
\end{abstract}

\section{INTRODUCTION}

For more than a decade since the so-called Porter-Fanning Debate, held as part of the Consultation on Biblical Greek Language and Linguistics at the 1991 SBL meeting in Kansas City, scholarly discussion of verbal aspect in New Testament Greek has been dominated by the issue whether or not the tense forms of the indicative mood semantically and systematically convey temporal reference.

The debate - and also the diverse reactions it engendered - was almost inevitable. The immediately preceding years had witnessed the publication of two comprehensive studies of Greek verbal aspect (Porter 1989; Fanning 1990) incorporating hundreds of samples from the New Testament as well as other Hellenistic texts (restricted to the LXX in the case of Fanning), both attempting to approach the subject systematically and within 
the framework of modern linguistic theory. The debate has contributed greatly to awareness among New Testament scholars of the advances that have been made in terms of scientific (modern linguistic) study of the language of the New Testament. (See the remarks of Carson and those of Schmidt in [Porter \& Carson 1993]. The contributions to that volume by Porter and Fanning themselves concern more general issues of definition and methodology, and include no reference to any of the New Testament passages discussed in detail in this study.)

Ironically, though, ensuing discussion has focused not on the central notion of 'aspect', but on questions about the relation of Greek verb (tense) morphology to temporal categories. The short article of Voelz (1993) is a notable exception. However, his alternative proposal would probably not find general agreement. Adopting the term 'focus' and visualizing aspect in terms of "focus upon" rather than "perspective from which" may seem feasible, but defining the distinction between the two major aspects as "focus upon a perceived relationship between the activity and the doer" versus "focus upon the act itself" (1993:159) ignores other means - like middle voice versus active, or even, on a syntactical level, finite versus infinitive forms - by which Greek normally grammaticalizes such a distinction. The article of Du Plooy (1991) altogether misses the point of the debate about verbal aspect and its relation to the tense forms of the Greek verb. Structuring his article according to Louw and Nida's (1988) list of semantic subdomains of "aspect", Du Plooy selects for discussion examples "from the whole of Luke-Acts" (1991:166), but ends up presenting mainly passages quoted by Louw and Nida (1988:1.655$664)$ themselves. His conclusion, that "tense form in itself is not a primary vehicle of aspect in Greek", shows that he misunderstands what Louw and Nida mean by 'aspect' as a semantic domain to which they assign mainly verbs, but also nouns, adverbs, and adjectives, which lexically realize aspect. In fact, by describing the verbs in this domain as denoting "merely an aspect of the action occurring in the verb complement", they make no claim to be presenting in domain 68 the totality of what is denoted by the term "aspect" in its relation to the different tense forms of the Greek verb.

Focus on the differences between the opposing views of Porter and Fanning has tended to hamper the application of aspect theory to the analysis of texts and the exploration of its exegetical implications. (This is not to say that nothing has been done in this regard. See, for instance, the contribution of Hauff listed in the bibliography.)

A survey of literature dealing with these issues reveals a tendency of growing polarization, proliferation of opposing arguments, terminological 
confusion, and an unfortunate focus on exceptions in attempts to prove or disprove the rule.

Rodney Decker, for instance, presents Porter's theory by two quotes from Porter's own works ("<In fact it appears that $>$ Greek does not grammaticalize tense in any of the three major tense categories" [Porter 1989:78], and "... Greek speakers ... had something other than temporal categories in mind with regard to what the verb form itself meant .... [They] could speak of when processes occurred, but they did not use verb forms alone to do so. They in stead used various other tools in their language. ..." [Porter 1996:38 = 1993:44-45]) (Decker 2001:2); then he interprets these as "it denies any temporal reference to the form of the verb"; and then straightaway (2001:2 n 8) quotes Silva's argument, that "regardless of one's theoretical approach to this issue, however, it is indisputable that, in fact, temporal reference is at least associated with the indicative forms in the overwhelming majority of cases, and it makes no sense whatever to ignore that element when analyzing the text" (Silva 1995:105). By this presentation Decker gives the impression that Silva is directly opposing the views of Porter. The truth, however, is that Silva does not even refer to Porter in that comment, but is merely cautioning readers with an exegetical interest not to disregard, on the basis of (Porter's) systematic semantic theory, the temporal implications featured on the level of language usage in particular contexts. Decker would have done well to mention that Porter himself also says: "The interpreter's task is to consider all of the relevant information - including verb tenses [my emphasis], discourse type and so forth - before deciding when [Porter's emphasis] an event is to be conceived of as occurring" (Porter 1992:26) and "The imperfect form ... is the closest that the Greek language comes to a form actually related to time (this does not mean that it is an absolute tense, however)" (Porter 1992:33-4).

\section{PURPOSE AND DELIMITATION OF THE SCOPE OF THIS STUDY}

This study is not intended to appoint (rather belatedly!) a winner/loser in the debate. By highlighting the growing confusion the author wants to emphasize the need for a closer reading and more thorough reappraisal of the aspect theories of both Porter and Fanning.

Of course it is impossible, within the scope of a study like this one, to trace the course of this debate paying due attention to all arguments, or covering the total area of application of the theories. Therefore the scope of this discussion will be limited to the so-called "non-past referring Imperfects". The reasons for this deliberate choice should briefly be stated: 
Firstly, why Imperfects? In the morphological system of the Greek verb, the Present and Imperfect form a contrastive pair to which both Porter (1989:207) and Fanning (1990:240) attribute the same aspect values. Logically, there must be some opposition between these two tense forms in terms of a semantic feature other than aspect (otherwise, why the duplication of forms and consequent redundancy within the system?). Fanning reflects the traditional view, regarding this opposition in terms of temporal reference (present versus past time). Porter rejects the traditional view, dealing with temporal reference as (exclusively) a function of usage within the context of utterances.

Secondly, why non-past referring Imperfects? This rarely (if at all) occurring category was chosen because past referring Imperfects do not highlight the issue, being easily explained within the theoretical frameworks of both Porter and Fanning. Porter's position would in all probability be that since contextual (deictic) indicators may establish past temporal reference, and since the "remote" tense form, when used in such contexts, is not at variance with those indicators, there is no need for comment (cf Porter 1989:188-89). Nor do present referring Presents highlight the issue (for the same reason); nor do past referring Presents (since traditional grammars all recognise categories, though differently defined, of "historic" Presents). Non-past referring Imperfects highlight the issue as follows: they are seen by traditional grammars (logically also by Fanning) as special cases, while seen by Porter as providing support for his non-temporal thesis.

To supporters of the traditional definition of the Imperfect as inherently a past tense form, these instances pose a problem: When the generally assumed semantic content of the tense form is seen to be cancelled (whether by contextual markers or by the inherent logic of the situation to which the linguistic utterance refers), the natural reaction is to attempt to explain the contextual or pragmatic factors effecting this cancellation. To Porter, advocating a radical revision of traditional views on the relation between tense forms and temporal reference, non-past referring Imperfects have special importance: He is compelled to cite examples which seem to support his thesis, and to interpret these without recourse to past temporal reference of the verb form, while demonstrating his interpretation to be at least plausible (cf Porter 1989:104).

Thus the question to be considered is this: Which side in the continuing debate deals with non-past referring Imperfects with the least complication of their theory? (cf Porter's claim in this regard [1989:239 - especially the last sentence].) 
A detailed comparison of Porter's views on the meaning and use of the Imperfect to those of Fanning is complicated, firstly, by their different theoretical perspectives. Fanning, approaching the discussion of aspect within the framework of the traditionally accepted time-based view of the Greek tense forms, defines the Imperfect in contrast to the Present:

The imperfect indicative is much like the present indicative in that it takes the basic aspect-value of the present ('internal viewpoint on an occurrence') and displays many of the same particular applications of this aspect. The major difference, of course, is that the imperfect moves this aspect-value into the past-time frame, since it indicates past tense (i.e. occurrence antecedent to the time of speaking). ... The three major uses of the imperfect ... are virtually identical in aspect-value to the corresponding categories of the present ...

(Fanning 1990:240-41)

Porter follows a different and, in a sense, more cumbersome route. In his discussion of the Imperfect ("Remote Imperfective Tense"), he firstly emphasizes that "the Aorist and Imperfect forms are best interpreted as realizing different semantic aspectual features. ... The Imperfect, semantically more heavily marked than the Aorist, is aspectually imperfective (...), also often occurring in past contexts as the foreground narrative tense" (Porter 1989:199). Then, moving to the semantic difference between the Imperfect and narrative Present, he asserts the following:

(1) There is no aspectual difference: both are aspectually imperfective on the basis of their formal paradigm. ... (2) A semantic distinction stems from a functional difference. ... [I]ts major usage is in narrative contexts .... Although this has led to the misleading generalization that the Imperfect is strictly a preterite (...), the abundant usage in past-referring contexts in relation to the aspectually identical Present, as well as the need for explanation of the persistence of two aspectually imperfective forms in Greek, points to a contextual distinction. It is at this juncture of usage alone that tense forms in Greek - the Imperfect and the Pluperfect approach time-based tense forms (...).

(Porter 1989:207)

A second factor complicating any direct comparison of Porter's thesis to that of Fanning is the difference in the way they present the evidence on which they base their respective arguments. Porter gives translations (his own - see 
below) of every text cited, and his comments follow immediately after each example. Fanning, on the other hand, cites groups of examples without translation and without individual comments, and discusses the use of the tense form in a summarizing way afterwards.

The third factor complicating this comparison is the difference in their relation to their target audience. Porter, self-consciously advocating a radical revision of traditional scholarly views, especially regarding the relation of Greek tense forms to time, anticipates counter-arguments and focuses on refuting these; while Fanning is much more at home among those with traditional views, and nowhere explicitly challenges Porter's thesis. In fact, he does not even mention Porter in his bibliography - clearly because he was unaware of Porter's book when his manuscript was being revised for publication during the spring of 1988. It is thus not surprising that Fanning does not deal systematically with a category of "non-past referring Imperfects", though he does cite and discuss a few of the same texts that Porter cites as examples of this category. Almost all of these are what he calls "“desiderative" Imperfects" (Fanning 1990:251), and he states by way of explanation that "the reference ... is actually present". (Porter discusses verbs with a "volitional lexical meaning" in Appendix 10B.)

As explained above, there are no direct objections to Porter's thesis to be found in Fanning's monograph; but diverse objections have been raised in subsequent discussions - some on the basis of theoretical or methodological issues, others focusing on Porter's treatment of specific examples of tense usage. Among these, one of the first is McKay (1992). Since specific responses of McKay to Porter's comments on non-past referring Imperfects will be drawn into this discussion, it is only fair first to present his general position vis-à-vis Porter:

The purpose of the present article is to question some of P.'s (= Dr. Porter's) assertions about the time values of some Greek passages, for it seems to me that in his enthusiasm to overthrow the old erroneous assumptions he sometimes goes too far, and either ignores or misapplies the contextual evidence. ... In what follows I select a number of passages on whose explanation I find myself in disagreement with him, and cite few on which I agree with him, but this imbalance does not mirror the relativity of my approval of even the chapters I focus on.

(McKay 1992:210)

A more unreservedly pro-Porter (or rather, anti-anti-Porter) position is taken by Decker (2001), whose purpose is "to summarize some of the major 
objections that have been raised regarding Porter's contention that the verb does not grammaticalize time and provide a response to those objections" (Decker 2001:4). With regard to non-past referring Imperfects, specifically, he applies the criterion of cancelability (cf Decker 2001:5) in an attempt to turn Olsen's objection on its head. Olsen argues that the temporal reference of some of the tense forms (e.g. past time reference of the Imperfect, present reference of the Perfect) cannot be cancelled. In other words, whenever an imperfect form is used, it invariantly signals the meaning of past time. "Porter's claim that they lack temporal reference comes from an overly simplified tense model" (Olsen 1994:255). Decker claims: "A counter-example would demonstrate that temporal reference can be determined pragmatically rather than semantically in these forms .... That is, the semantic meaning which Olsen proposes can be cancelled. If so, this would suggest that the true semantic meaning of the imperfect and perfect is not to be equated with temporal reference, but with aspect" (Decker 2001:13). This seems a reductio ad absurdum. The view can hardly be upheld that a single exception can nullify a rule applying to hundreds of instances. Decker's view is an oversimplification which disregards possible collaboration of the context and imperfect tense form to establish past temporal reference. He goes on to cite and discuss a few counter-examples, but all of these involve Imperfects of

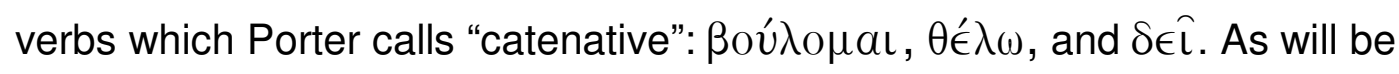
seen in the following discussion, all Porter's examples except one belong to this class. This in itself should caution the reader against regarding these examples as representative of a generally demonstrable feature of the imperfect tense form.

\section{DISCUSSION OF SPECIFIC EXAMPLES OF ALLEGEDLY NON-PAST REFERRING IMPERFECTS}

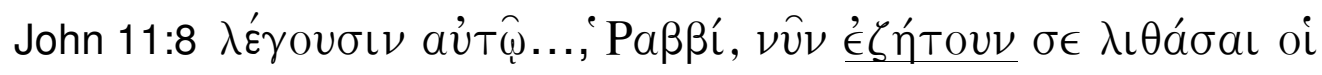

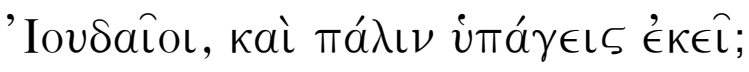

This is the first of thirteen New Testament texts cited by Porter as examples of non-past referring Imperfects. He comments as follows: "(..., "Rabbi, the Jews are now seeking to stone you, and again you are going there?"), with the nonremote imperfective (Present) being stressed over the remote imperfective and the deictic indicator $(\nu \hat{v} \nu)$ establishing the temporal sphere of reference" (1989:210).

Decker (2001:13-14, n 61 \& n 70) does not discuss or even mention this text. Does this betray a pro-Porter bias - defending Porter's thesis with 
reference to the texts on which he agrees, but ignoring the rest? He starts his discussion with the remark: "There are not many examples of nonpast referring imperfect forms, but there are some that appear to be legitimate."

McKay (1992:213) rightly asserts that "the past reference must be

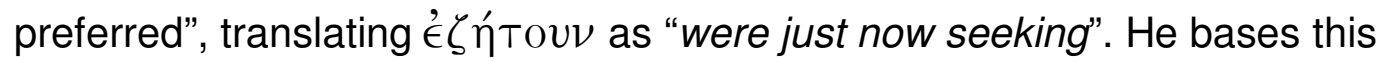
preference on the immediate context (a double attempt by the Jews to stone Jesus is recorded in John 10:31-41) and on the observation that "the use of $\nu \hat{v} \nu$ to refer to a recent (but not present) activity is attested from Homer on".

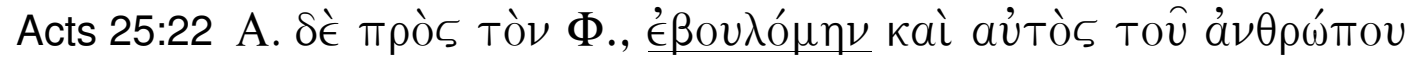
ákôे $\sigma a \iota$

Porter adds the following comment (1989:210): "(A. to F., I myself am wanting to hear the man), where the less heavily semantically marked remote imperfective seems appropriate to Agrippa's expressing reticent curiosity ... (1 Tim 2:8; Titus 3:8, with the Present; cf. 2 Cor $1: 15 \ldots$ with the deictic indicator establishing past reference)." To be sure, Porter's added examples from 1 Timothy and from Titus have very little, if any, relevance to the use of the Imperfect in Acts 25:22; and unless the deictic indicator ( $\pi \rho{ }^{\prime} \tau \in \rho O \nu$ ) in 2 Corinthians $1: 15$ can be proven to be the sole indispensable element establishing past reference, this verse does not support Porter's argument (which is based on implicitly denying this Imperfect form any past reference).

McKay (1992:213) says that "if '́ $\beta o v \lambda o ́ p \eta \nu$ means am wanting it does not express any reticence." He considers it "an example of a phenomenon, common also in earlier Greek, which does express reticence: either I would like to hear/have heard or I wish I could hear/have heard, ..., the latter with the excluded wish notion belonging to the subordinated infinitive transferred to the governing verb ...." His criticism of Porter is of course to the point: If the clause is felt to express reticence on the part of Agrippa, why translate it in a way that does not reflect this - unless in a deliberate attempt to deny the Imperfect from any inherent (or even implicated) temporal reference? However, McKay does not succeed in explaining why and how, in this context, the Imperfect expresses reticence. (Incidentally, that an excluded wish notion

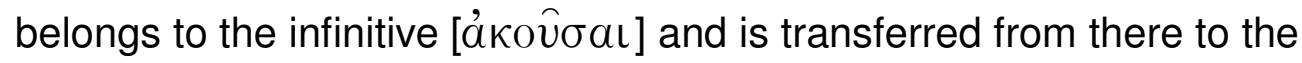
governing verb [' $\beta \beta O u \lambda o ́ \mu \eta \nu]$, seems utter nonsense. The 'wish' notion is

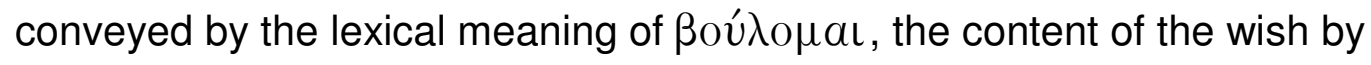
ákoú $\omega$, and any notion of 'exclusion' - excluded realization of the hearing, not of the wishing - is contextually determined.) 
In my opinion, Agrippa's wish as reported in 25:22a was an immediate ("present") reality and overtly expressed - note Festus' response in verse 22b - yet the dynamics of the dialogue would render the use of the Present form

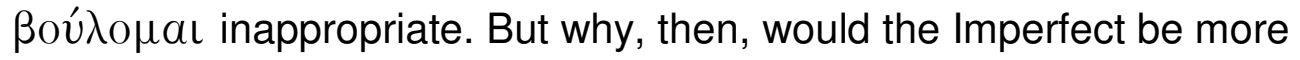
appropriate, if it does not signify some meaning distinctly different from the Present? The answer must be that the Imperfect, occurring in a context where it is not normally used, adds markedness to the expression. It draws attention to the wish - inviting, as it were, the addressed to consider its implications. It is not the reality of the wish, but the register of the entire statement that is affected by the use of the Imperfect. (Decker [2001:13] says "the statement expresses to Festus a request to hear Paul" - to which I agree in terms of the notion of "speech acts" - but he does not explain how this speech function relates to the use of the Imperfect.)

Fanning (1990:250-51) cites this text (note: under the heading "Uses of the Imperfect Indicative"), along with others discussed below, as examples of the "conative imperfect" used of "actions which were not actually begun, but were intended, contemplated, or desired in the scope of past time which is in view." The majority of texts included in this short list are examples of "the socalled "desiderative" imperfect", which he describes as "another idiom with the imperfect which seems to fit under this category of conative use". Attempting to explain the use of the Imperfect (which he regards as a past referring tense) in these expressions of which the reference "is actually present" (1990:251), Fanning notes "a rhetorical shift in the time-reference: a present situation is portrayed as though past, in order to make it more remote and thus reduce the force of the statement."

As explained above, the use of a tense form that portrays the "situation" as though past, or makes it "more remote", introduces an element of tension between the present (or non-remote) situation and the remote tense form of the verb - thus not reducing the force of the statement, but highlighting it.

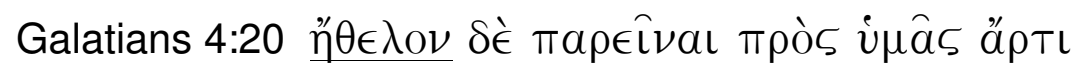

Porter comments as follows: "(and I want to be present with you now), with ä $\mathrm{T} \tau \mathrm{l}$ establishing present reference" (1989:210).

Fanning (1990:251) cites this example, quoting as far as ä $\rho \tau \iota$, but does not specifically comment on the seeming disparity between the present reference of the adverb and the use of the Imperfect. McKay interprets this as

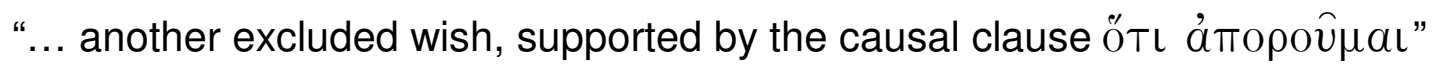


(1992:213). The causal clause emphasizes the wish, not the excluded realization of its content.

Decker (2001:13) is at pains to point out that the deictic indicator ä $\rho$ Tı

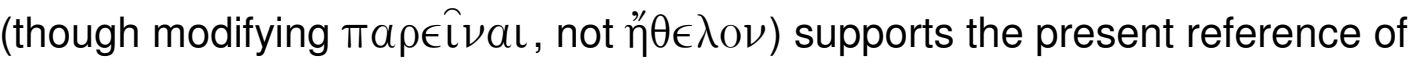
the context. In this he merely echoes Porter's opinion. He goes on to warn that any notion of potentiality should not be attached to $\eta \theta \epsilon \lambda \mathrm{o \nu}$, but focused on $\pi \alpha \rho \in \hat{\imath} \nu a l$. In this respect he is correct: The wish is real, while the realization of its content is highly improbable. The usual way to express this in English is "I wish I could have been with you". One should not be confused by the different way the same meaning is expressed in Greek.

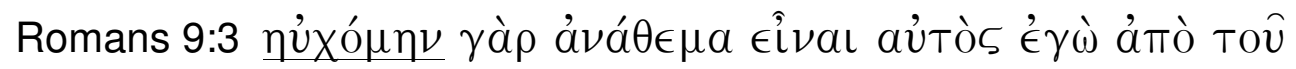
Xрıбтой...

Porter comments as follows: "(I indeed pray to be anathema from Christ ...), probably with timeless use of the Imperfect ... establishing Paul's attitude toward his own people, although an "epistolary" Imperfect is also possible" (1989:210).

McKay (1992:213) improves Porter's translation of this clause to "I could pray that I should be" and explains it also in terms of an "excluded wish" (see above).

Of the seven occurrences of the simplex $\in \ddot{\chi} \chi 0 \mu a \mathrm{l}$ in the New Testament, those meaning "pray" are syntactically marked. In its unmarked meaning "wish"/"desire", $\epsilon \ddot{\cup} \chi \chi \mu \mu$ is is almost synonymous to $\theta \epsilon ́ \lambda \omega$ or

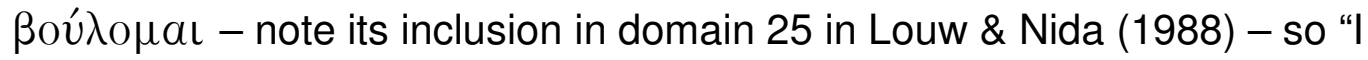
would wish to be ... (if that were possible)" or "I wish I could have been ..." seems a more accurate translation, and the comments on Galatians 4:20 apply to this passage as well.

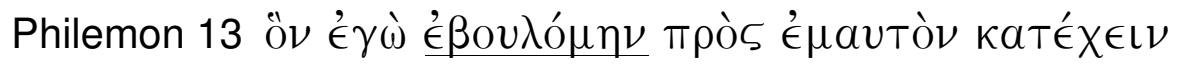

Porter comments: "(whom I myself want to retain for myself), where Paul uses four parallel relative clauses, the first being past in reference ( $v 10)$, but the subsequent three present (the second and fourth verbs are Aorists)" (1989:210-11). McKay suggests a correction to Porter's translation - "(wish I could rather than P.'s want)" (1992:213) - but offers the same (unconvincing) explanation for this Imperfect as for Acts 25:22.

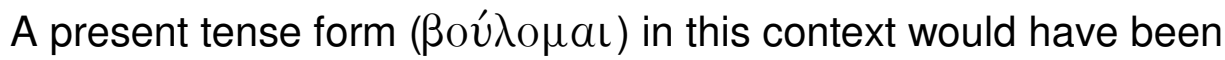
perplexing to the addressee - why say one thing ("I want to keep Onesimus") 
while doing another (sending him back to Philemon)? The Imperfect Ł́ßou入ó $\mu \eta \nu$ reveals the sender to be aware of this tension between wish and actual situation - and upon further reflection, the addressee understands that the sender's expressed wish has been made subordinate to other considerations.

Though one notices contextual (situational) differences when considering the last four passages above, the one obvious common feature is the significance of the use of the Imperfect. Porter's treatment of these passages as if this tense form had no meaning distinct from the Present results in misinterpretation of the text.

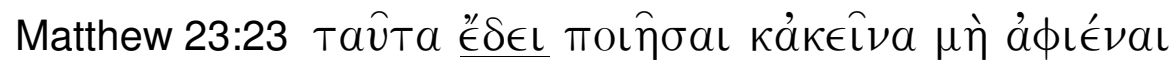

Here, according to Decker, "a temporally unrestricted reference (perhaps more specific, omnitemporal use) is probably in view" (2001:14). He is clearly following in the footsteps of Porter (1989:211): "(it is necessary to do these things and not to neglect the others), with omnitemporal reference."

Decker (2001:14) argues as follows: "Jesus describes a standing obligation by use of the imperfect - the perpetual relevance makes better sense of this interchange than merely reflecting a past obligation, even if continuing relevance is suggested." In this he follows Olsen's explanation of "continued relevance" (Olsen 1994:290). I do not agree. The dynamics of this interchange is not that of straightforward moral teaching, but of reproach. Note

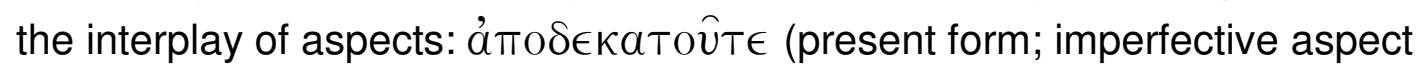

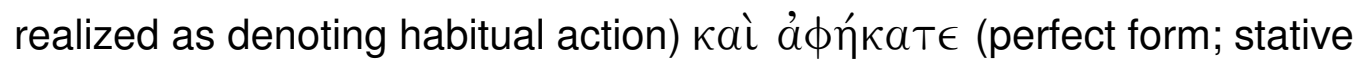
aspect realized as a state of affairs resulting from a preceding action) Tav̂Ta Ł̌ $\delta \in \mathrm{L}$ (imperfect form; no alternative aspect available for choice, thus no aspectual significance; obligation existing at the time of the action expressed

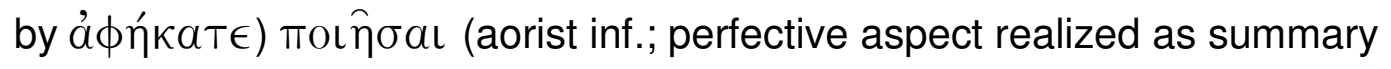

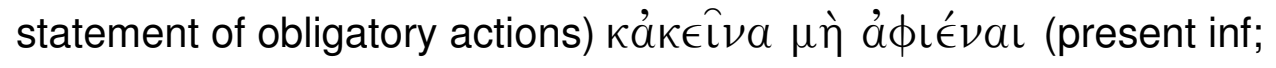
imperfective aspect realized as denoting habitual action, or action distributively affecting multiple objects [cf Fanning 1990:168]). The chiastic structure of this passage (habitual tithing - neglect of important aspects of the law - obligation to do Tav̂ta, i e what the law requires - not neglecting

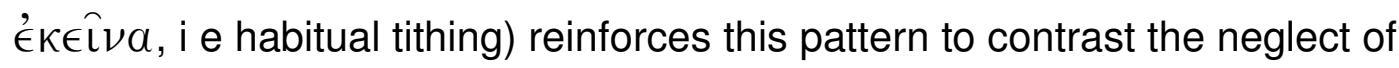
important aspects with the habitual observance of trivialities, however commendable. On this point I agree with McKay (1992:215), though the rest of his explanation is hard to follow, and ends with allowing the Imperfect 
present time reference - it really is necessary - showing the same insensitivity to context as that of which he accuses Porter.

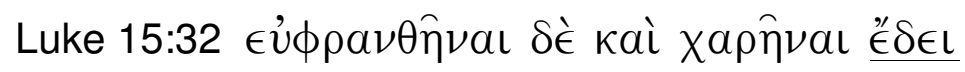

Porter (1989:211) seems to have no difficulty with explaining this passage: "(it is necessary to rejoice and be glad), since the party is currently being held."

Fanning (1990:394) cites this passage in a different context. While explaining the aorist aspect of the "STATIVE" infinitives as having "ingressive" sense, he seems to accept the past time reference of the Imperfect as undisputed. As stated earlier, Fanning does not provide a translation; but his categorization of this example could only make sense if the clause is understood as "We should have become joyful and glad ..." (expressing the propriety of entering into the relevant state, as everyone except the elder son has done).

There is another plausible way of interpreting this clause, however: "You should have been joyful and glad ..." (with the implied accusation of not reacting appropriately to the return of the younger brother). Note, "you" (sg) in stead of "we" $-\delta \in \hat{\imath}$ is impersonal - supported by the following clause, "for this brother of yours ...". This results in a climactic end to the parable, as opposed to the rather feeble explanation by the father, "it was necessary (for us) to start rejoicing", as McKay (1992:217) would have it. (In fact McKay is aware of the implication: "by calling him your brother he [the father] also implies that you ought to rejoice, but does not actually say so.")

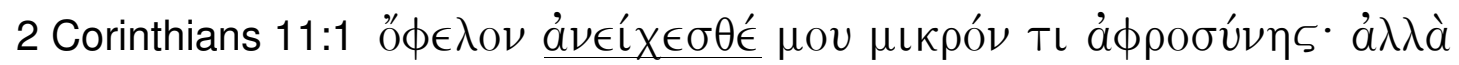
кaì àvé $\chi \in \sigma \theta \epsilon$

Louw (1988:1.671) renders this "would that you would grant me a little bit of foolishness" or - since "in a number of languages it may be preferable to translate ${ }^{\circ} \phi \in \lambda \mathrm{O} \nu$ as simply an expression of wishing" - "I wish you would grant me ..." Note that Louw \& Nida intend this rendering of the clause merely to be a practical aid to translators. The construction with ó $\phi \in \lambda o \nu$ may imply, but does not express, a wish on the part of the speaker. This should be kept in mind when considering Porter's (1989:210) comment: "(would that you would be patient with my foolishness for a little while; but indeed you are patient with $\mathrm{me}$ ), where Paul expresses his current wish that the Corinthians would be patient with him, while acknowledging that in fact they are patient with him." 
McKay (1992:213 n 9) agrees with Porter about the temporal reference of this Imperfect, but would correct Porter's translation to "would that you were patient".

If there were no semantic distinction between this Imperfect and the Present $\alpha \dot{\nu} \epsilon^{\prime} \chi \in \sigma \theta \in$ in the immediately following $\alpha \lambda \lambda \alpha \alpha^{\prime}$... clause, the result would be an outright contradiction. Neither Porter nor McKay offers any helpful explanation.

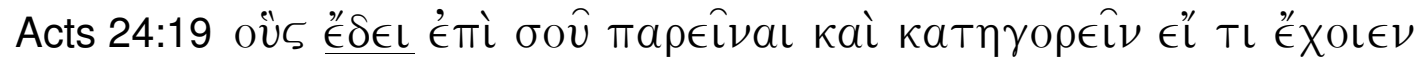

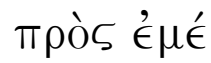

Porter (1989:211): "(... for whom it is necessary to come before you and to make accusation if they might have something against me), with present reference indicated by the clause using the Imperative in $v 20$." Porter ignores the rhetorical shift, marked by $\ddot{\eta}$ at the beginning of verse 20 (î̀ aúToì oîto

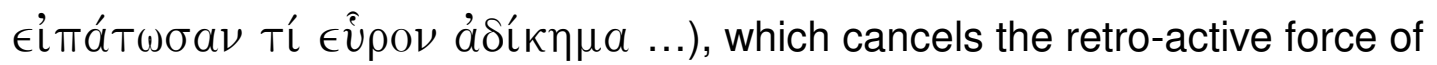
present reference which he claims. If verse 20 began with oûv, Porter's argument would have been more convincing. As the text reads, the Imperfect collaborates with the Optative " $\chi \chi O \iota \in V$ in the protasis to mark a contrary-tofact conditional statement.

To summarize: The rhetorical effect of most, if not all, of the above passages would be minimized - indeed lost - were it not for the tension generated between present (real time) reference of the context and the inherently past referring meaning of the Imperfect form.

One example which Porter quotes as a "non-past referring Imperfect" but which reveals an obvious blunder in his argument, is (intentionally?) not

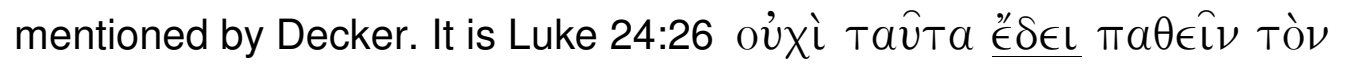

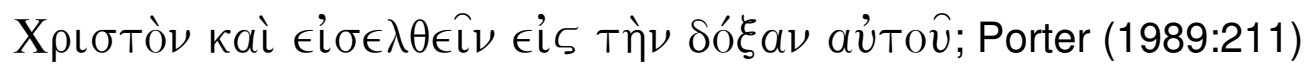
comments: "(are these things not necessary, that is for the Christ to suffer and to enter into his glory?), with a timeless use of ${ }^{\prime \prime} \delta \in \mathrm{l}$ in the mouth of the risen Jesus." The Imperfect " $\delta \in \mathrm{L}$ is not used timelessly here; the risen Jesus, speaking of the necessity of his passion, clearly refers to a necessity that existed in the past - up to the point of the occurrence of that passion.

The only way that the temporal reference of $" \epsilon \in \mathrm{L}$ in this context could be construed as "timeless" is by separating the two propositions as follows: "It was necessary - was it not? - for the Christ to suffer; and it is necessary - is it not? - for the Christ to enter into his glory." Then the second proposition (containing a second, implied $\epsilon^{\prime} \delta \in \mathrm{l}$, or $\delta \in \hat{\epsilon}$, for that matter) may be understood as having present (continuing) relevance. Porter, however, interprets $\epsilon^{\prime} \delta \in l$ as 
governing both infinitives jointly - a much more likely interpretation - and thus presents here an Imperfect with contextually marked past time reference.

\section{CONCLUSION}

It would seem, then, that Porter's discussion of the New Testament texts cited as examples of "non past-referring Imperfects" does not lend undisputed support to his denying the tense forms inherent semantic temporal reference. On the other hand, the counter arguments of some supporters of the traditional view of the Greek tense forms as time-based (the anti-Porter side) are also often flawed, leading to growing confusion rather than bringing more clarity. This confusion is compounded in turn by attempts to defend Porter against objections to his thesis (the anti-anti-Porter position of Decker, for instance). It is hoped that the discussion in this paper has at least suggested some possible routes of escape from this deadly spiral.

\section{Works consulted}

Carson, D A 1993. An introduction to the Porter/Fanning debate, in Porter \& Carson 1993:18-25.

Decker, $R \mathrm{~J}$ 2001. Verbal aspect in recent debate: Objections to Porter's nontemporal view of the verb, presented at Evangelical Theological Society Eastern Region Annual Meeting, 3/30, Philadelphia Biblical University, Langhorne, PA. http://faculty.bbc.edu/rdecker/documents/PorterObj.pdf

Du Plooy, G P V 1991. Aspect and Biblical exegesis. Neotestamentica 25(1), $157-$ 170.

Fanning, B M 1990. Verbal aspect in New Testament Greek. Oxford: Clarendon Press. (Oxford Theological Monographs.)

Fanning, B M 1993. Approaches to verbal aspect in New Testament Greek: Issues in definition and method, in Porter \& Carson 1993:46-62.

Hauff, Thomas R 1996. Assessment and application of the systematic linguistic model of verbal aspect in the New Testament proposed by Stanley E Porter. Th $\mathrm{M}$ thesis, Western Conservative Baptist Seminary.

Louw, J P \& Nida, E A (eds) 1988. Greek-English lexicon of the New Testament based on semantic domains. 2 vols. Cape Town: United Bible Societies.

McKay, K L 1992. Time and aspect in New Testament Greek. Novum Testamentum 34(3), 209-228.

Olsen, M 1994. A semantic and pragmatic model of lexical and grammatical aspect. $\mathrm{PhD}$ dissertation, Northwestern University.

Porter, S E 1989. Verbal aspect in the Greek of the New Testament, with reference to tense and mood. New York: Peter Lang. (Studies in Biblical Greek 1.)

Porter, S E 1992. Idioms of the Greek New Testament. Sheffield: Sheffield Academic Press. (Biblical Languages: Greek Series 2.)

Porter, S E 1993. In defence of verbal aspect, in Porter \& Carson 1993:26-45.

Porter, S E 1996. Studies in the Greek New Testament. New York: Peter Lang. (Studies in Biblical Greek 6.) 
Porter, S E \& Carson, D A (eds) 1993. Biblical Greek language and linguistics: Open questions in current research. Sheffield: Sheffield Academic Press. (JSNT Supplement Series 80.)

Porter, S E \& Carson, D A (eds) 1995. Discourse analysis and other topics in Biblical Greek. Sheffield: JSOT Press. (JSNT Supplement Series 113.)

Schmidt, D D 1993. Verbal aspect in Greek: Two approaches, in Porter \& Carson 1993:63-73.

Silva, M 1993. A Response to Fanning and Porter on verbal aspect, in Porter \& Carson 1993:74-82.

Silva, M 1995. Discourse analysis and Philippians, in Porter \& Carson 1995:102-106. Voelz, J W 1993. Present and aorist verbal aspect: A new proposal. Neotestamentica 27(1), 153-164. 